\title{
High speed digital recording of plasma-gas dynamic processes in supersonic channel flow
}

\author{
I.A. Znamenskaya ${ }^{1}$ I.V. Mursenkova ${ }^{2}$, I.A. Doroshchenko3 \\ Lomonosov Moscow State University \\ ${ }^{1}$ ORCID: oooo-0oo1-6362-9496, znamen@phys.msu.ru \\ 2 ORCID: 0000-0002-7181-4533, murs i@physics.msu.ru \\ 3 ORCID: 0000-0002-0488-0020, doroshenko.igor@physics.msu.ru
}

\begin{abstract}
$\underline{\text { Abstract }}$
We discuss the results of the visualization of dynamic processes that occur when a pulsed volume discharge concentrates in front of the shock wave in the rectangular channel. Panoramic visualization of the high-speed processes was carried out with a high temporal resolution - in the nanosecond range - based on high-speed recording of the discharge glow by electron-optical cameras, as well as in the microsecond range - using high-speed shadow imaging. We obtained discharge glow images in optical range during the discharge electric current flow and in the afterglow mode. The electron-optical camera exposure was $100 \mathrm{~ns}$. The flow pattern after pulse ionization of the plane shock wave corresponds to the $1 \mathrm{D}$ Riemann problem solution. The flow was visualized by the high-speed shadowgraphy with frame rates from 100 ooo to 525 00o. We made digital processing and analysis of the obtained frames. We compared data obtained with different cameras in nanosecond and microsecond time range and plotted space-time curves of the discontinuities movement. 1D CFD profiles were compared with the experimental data.
\end{abstract}

Keywords: flow visualization, panoramic imaging techniques, high-speed shadowgraphy, shock waves, contact discontinuities, combined nanosecond discharge.

\section{Introduction}

The interaction of pulsed or pulsed-periodic gas discharges with shock waves is often investigated due to the possibility of applying the obtained results in plasma actuators and in solving practical problems. For example, using optical methods, it was shown [1] that the initiation of a gas-discharge plasma in front of a model that has a cone shape placed in a supersonic flow moves the shock wave from the model. This effect can be used to attenuate the negative impact of the shock wave on the environment when designing supersonic aircraft. When studying the interaction of a nonequilibrium plasma medium (gas-discharge plasma of volume and surface discharges) with shock waves (Mach numbers from 2 to 7), the effect of broadening the shock wave and splitting it into several gas-dynamic discontinuities was detected by shadow imaging [2-3]. It was theoretically shown that with the aid of fast local $(\mathrm{t}<1$ $\mu \mathrm{s}$ ) heating of the flow, the shock wave can be destroyed if the threshold energy input for a given shock wave intensity and flow parameters is exceeded [4]. Such a fast energy input to the flow can be created using gas discharges.

Schlieren or shadow methods are often used to visualize gas flows with shock waves [5-7]. In the present paper, the shadow method was used. The intensity distribution recorded by the shadow method corresponds to a second-order spatial derivative (Laplacian) of the refractive index $\mathrm{n}$, thus, this method allows visualizing gas-dynamic discontinuities, such as, for example, shock waves and contact discontinuities. In recent decades, digital high-speed cameras have been replaced by digital cameras, their recording speed reaches 10 million frames per 
second [8]. Transition to the digital format allows us to significantly speed up the processing and systematization of the results. In the present work, a high-speed digital camera was used for high-speed shadow imaging of gas flow in the microsecond range. The maximum recording speed was 525000 frames / s. The processes associated with the glow of a pulsed discharge occur, as a rule, in the nanosecond time range [9]. In order to register the discharge glow electron-optical cameras were used. The distribution of the discharge glow in the discharge chamber volume depends on the flow parameters inside it, since the electrical conductivity of air depends on the density, which is different at different points in the flow. Thus, the discharge itself allows visualization of some features of the flow, for example, the positions of gas-dynamic discontinuities [10].

In the present study we used optical panoramic methods to investigate the discontinuity breakdown on a front of a flat shock wave after its pulse ionization by the nanosecond volume discharge. Self-localization of the discharge occurs in front of the shock-wave, due to a density jump behind it. Thus fast ( $t<1 \mu \mathrm{s}$ ) gas heating in front of the shock wave occurs. As a result, two gas volumes with different gas-dynamic parameters arise on both sides of the shock wave front, and as the result the shock wave splits into several discontinuities: two shock waves and a contact discontinuity. This phenomenon is known as the "Riemann problem" [11]. Single images of the flow after the discontinuity breakdown at the front of a moving shock wave in a channel were first obtained by shadow methods in the study of prof. Znamenskaya et al. [12-14]. In the present study, we move forward and analyze consequent shadow frames of the flow under consideration and compare them with the corresponding glow images of the discharge in the nanosecond time range.

\section{Experimental setup}

Scheme of the experimental setup, as well as the flow visualization and synchronization systems are shown in fig. 1. We used the same setup as in [12]. The main part of the experimental setup is a discharge chamber mounted into the low pressure section of the shock tube. The discharge gap has a rectangular cross-section of $24 \times 48 \mathrm{~mm}^{2}$. The discharge gap length is $100 \mathrm{~mm}$. The discharge voltage is $25 \mathrm{kV}$. The electric current amplitude is about $1 \mathrm{kA}$, its duration is $200-300$ ns. A combined pulsed volume discharge with pre-ionization by ultraviolet glow from plasma electrodes located on the top and bottom walls of the discharge chamber was used. The discharge operates in single pulse mode. The side walls of the discharge chamber are made of quartz glass for optical access. Air was used as a working gas in all experiments. The synchronization system allows us to adjust the pressure before the shock wave front, set its velocity and start the discharge at any position of the shock wave inside the discharge gap. The Mach number of the rectangular shock wave generated in the shock tube ranged from 2.2 to 4.8 , the pressure in front of the shock wave was set to $\mathrm{p}=2-25$ Torr. A stationary laser with a wavelength of $532 \mathrm{~nm}$ was used as the light source in the shadow scheme. Videos were recorded by a high-speed camera with a recording speed from 100000 to 525 ooo frames per second. 


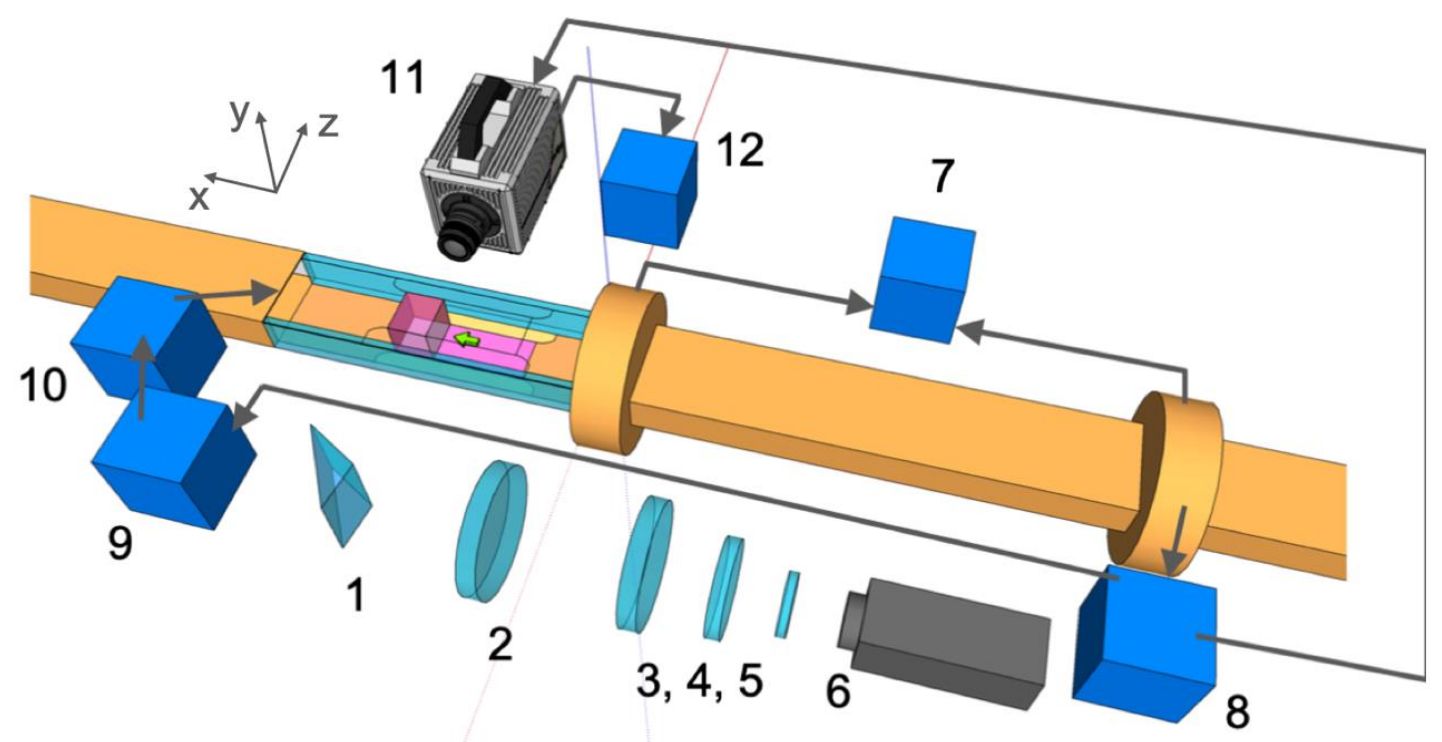

Fig. 1. Experimental setup with the shadow optical scheme and synchronization system. 1 light direction control prism, 2 - converging lens, 3,4,5 - scattering lenses, 6 - light source (laser), 7 - oscilloscope connected to the pressure sensors, 8, 9- pulse generators, 10 - high voltage discharge initiator, 11 - high speed camera, 12 - PC

The integral images of the discharge glow were recorded with the aid of a digital photo camera (fig. 2). Photographs of the discharge contain information on the time-integral distribution of the glow in the region under study. We used BIFO Ko11 high-speed electron-optical camera to obtain 9-frame images of the discharge plasma glow with a nanosecond time resolution (the minimum time interval between frames was $100 \mathrm{~ns}$, the frame exposure was 100 $\mathrm{ns}$ ). This made it possible to visualize the initial stage of the discontinuity breakdown at the front of the initial shock wave. While registering the discharge glow, shadow imaging was not performed, the electron-optical camera was placed in position 11 (fig. 1) The spectral range recorded by photo cameras and an electron-optical camera is $400-800 \mathrm{~nm}$.

\section{Localization of the pulse volume discharge}

The configuration of the combined discharge depends on the gas flow parameters inside the discharge chamber. If the air inside it is quiescent and the pressure does not exceed 100 Torr, the discharge glow is uniformly distributed over the volume of the discharge gap (fig. 2, a). If there is a shock-wave inside the discharge chamber at the moment of initiation of discharge, the discharge is localized in front of it (fig. 2, b-c). This is due to differences in the gas ionization rate on both sides of the shock wave front due to the density jump, described by the Rankine - Hugoniot relations [15]. Thus the discharge electric current and Joule heating occurs only in front of the shock wave. $[13,14]$. As a result, two gas volumes with different gas-dynamic parameters arise on both sides of the front, that is, conditions for the formation of a discontinuity breakdown are posed (Riemann problem) [11]. 

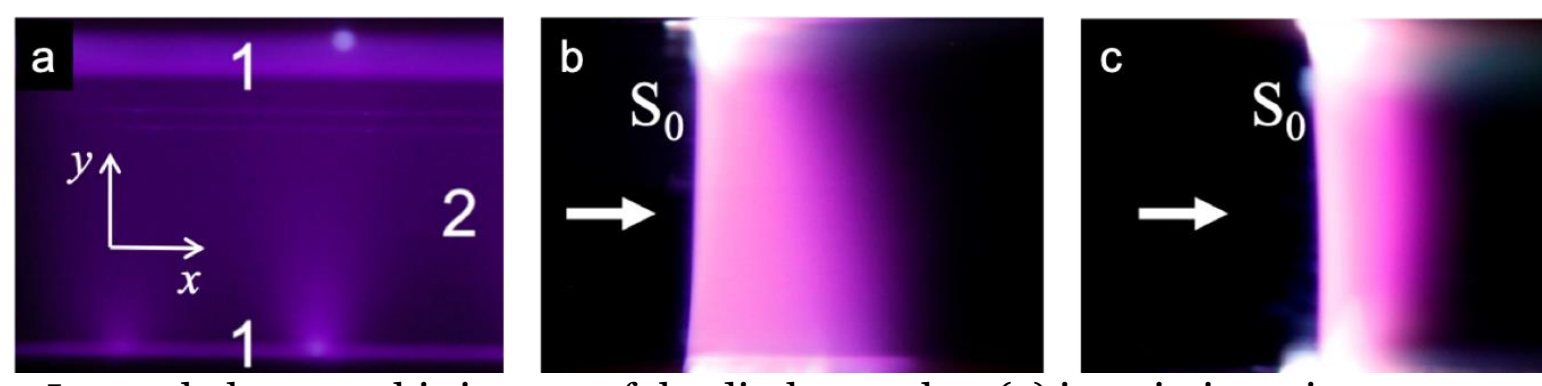

Fig. 2. Integral photographic images of the discharge glow (a) in quiscient air at a pressure $p$ $<100$ Torr, (b) when localized in front of the shock wave front with Mach 4.7 and distance from the shock wave front to the end of the discharge gap at the moment the discharge of 1.3 $\mathrm{cm}$, (c) with localization in front of the shock wave front with Mach 4.8 and distance from the shock wave front to the end of the discharge gap at the moment the discharge $0.6 \mathrm{~cm}$. The arrow indicates the direction of the shock wave front and gas flow behind it: 1 - surface discharges glow (plasmas sheets) 2 - volumetric discharge glow

\section{High-speed shadow imaging}

In order to study the gas flow with discontinuities, a shadow optical scheme was used. The flow after nanosecond ionization of the shock wave front So was visualized in the time interval from 1.5 to $63 \mu$ s with the aid of high-speed shadow imaging. Sequential sets of shadow images taken at regular intervals are shown in fig. 3. The exposure of each frame was $1 \mu$ s. The frames show how the initial discontinuity $S_{o}$ (initial shock wave) splits into three discontinuities, corresponding to the solution of the Riemann problem: shock waves $S_{1}$ and $S_{2}$ and the contact surface C. Each visualized discontinuity is a local gas density jump, visualized with shadow technique [5]. Frames in fig. 3, a were obtained at equal serial intervals of $6.7 \mu \mathrm{s}$ and have the highest spatial resolution. There are clearly visible shock waves propagating from the surface discharge (plasma sheets) $[12,13]$. After 10-15 $\mu \mathrm{s}$, they reach the axis of symmetry of the flow. Up to this moment, the flow along the $\mathrm{X}$ axis can be considered one-dimensional. Fig. 3, b shows a set of shadow images taken at a maximum recording speed of 525000 frames / $\mathrm{s}$, that is, the time interval between frames is $1.9 \mu \mathrm{s}$. In the second frame of this series there is a discharge glow, after that we can see that the front of the shock wave splits into 3 discontinuities. 


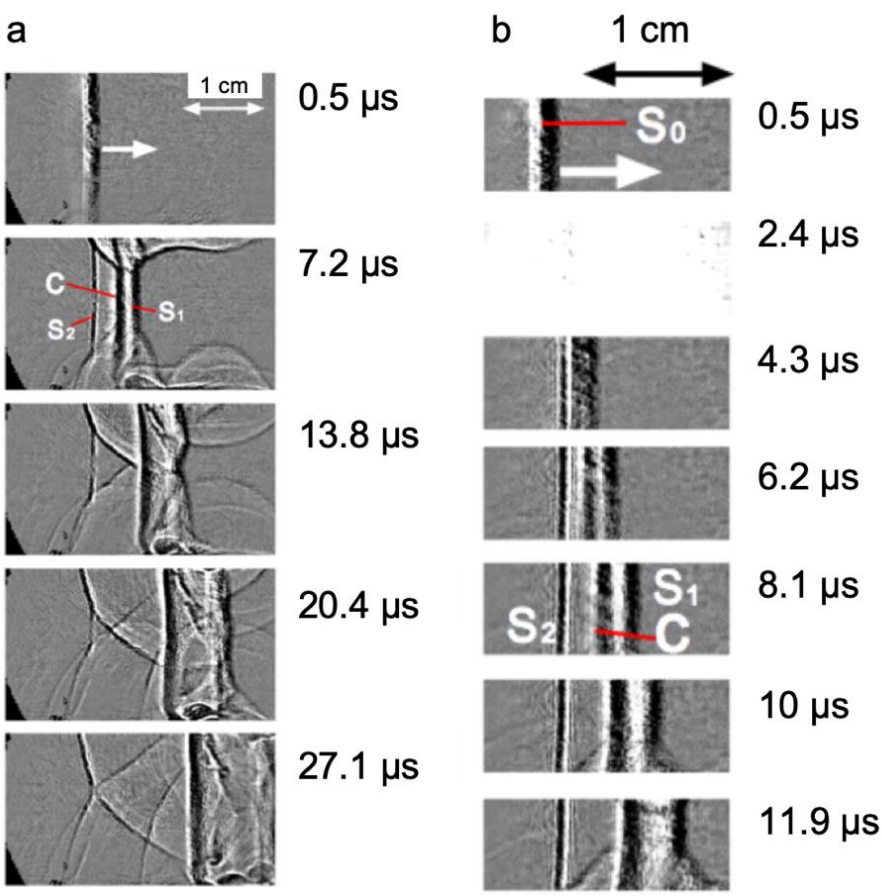

Fig. 3. The series of shadow images of the plane shock wave with a Mach number of 2.3 breakdown. Distance from the front of the original shock wave to the end of the discharge gap at the initial time moment is $2 \mathrm{~cm}$. Recording speed: a - 150000 frames / s, b - 525000 frames / $\mathrm{s}$

The $x$-t diagram of the discontinuities dynamics from fig. 3 is plotted in fig. 4 . The measurements were carried out relative to a fixed coordinate system rigidly connected with the shock tube (experimental setup). The distance along the OX axis is measured from the position of the shock wave front at the moment of discharge. The $\mathrm{x}$-t diagram shows that the velocity of the shock wave $S_{1}$ is maximum. It, as well as the contact discontinuity $\mathrm{C}$, moves in the positive direction of the $\mathrm{x}$ axis. The shock wave $\mathrm{S}_{2}$, moving against the incident flow, can move relative to the laboratory coordinate system in the positive, negative direction of the $\mathrm{x}$ axis or remain stationary depending on the Mach number of the original shock wave $S_{o}$.

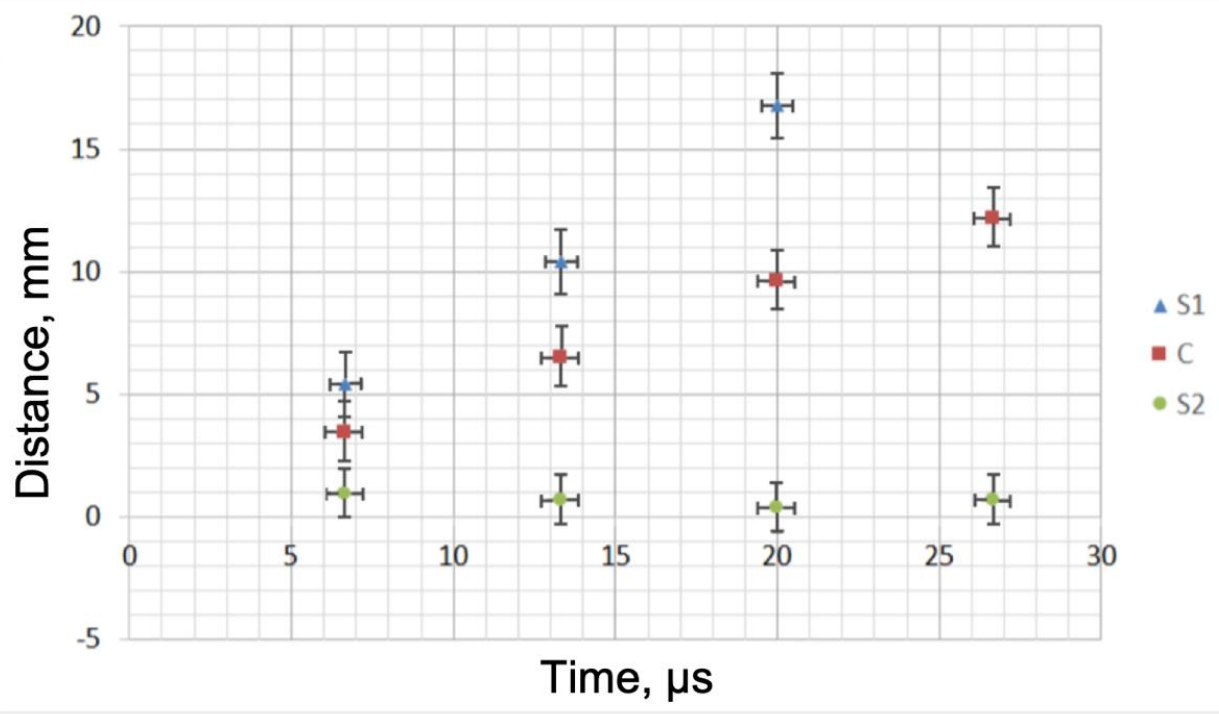

Fig. 4. The $\mathrm{x}-\mathrm{t}$ diagram of the movement of the discontinuities formed after the breakdown of the initial shock wave with a Mach number of 2.3 and a distance of $2 \mathrm{~cm}$ from the front of the initial shock wave to the end of the discharge gap at the initial time moment. 
Fig. 5 shows the flow development images at large time scales (up to $63 \mu \mathrm{s}$ ). The high-speed camera was moved $3 \mathrm{~cm}$ in the direction of the shock wave movement. As a result, the formation of instabilities and vortex structures near the channel walls in the flow behind the shock wave $S_{1}$ was visualized. The black triangle indicates the reference position for distance measurements.
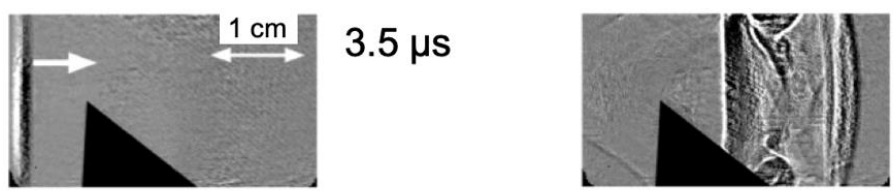

$36.5 \mu \mathrm{s}$

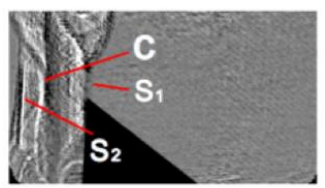

$10.1 \mu \mathrm{s}$

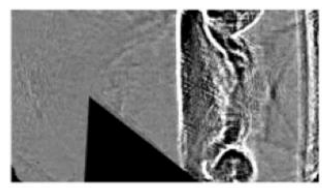

$43.1 \mu s$

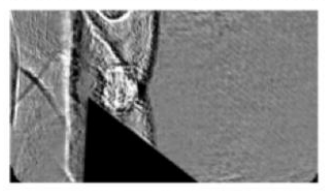

$16.7 \mu \mathrm{s}$
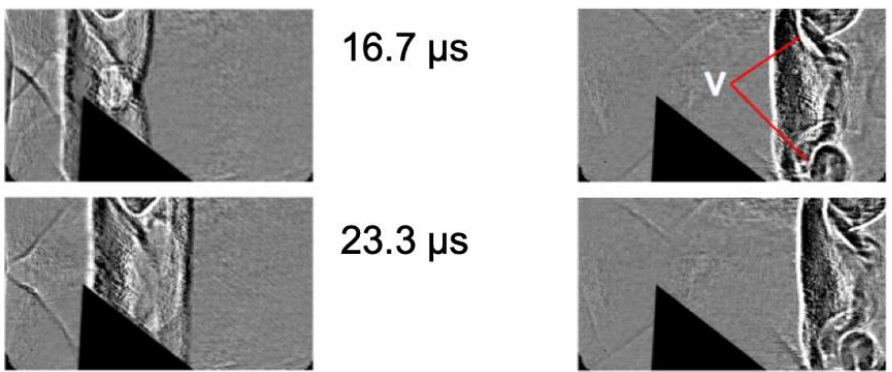

$23.3 \mu \mathrm{s}$

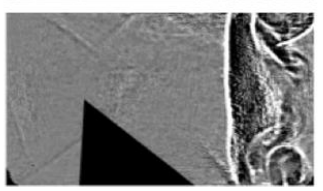

$49.7 \mu \mathrm{s}$

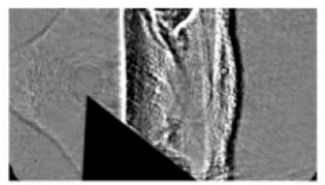

$29.9 \mu \mathrm{s}$

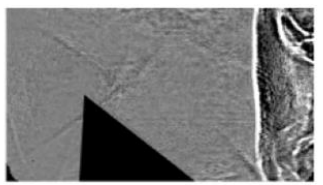

$62.9 \mu \mathrm{s}$

Fig. 5. A series of shadow images of the shock wave front breakdown. The Mach number is 2.2. Distance from the shock wave to the end of the discharge gap at the moment of discharge is $2 \mathrm{~cm}$. The recording speed is 150000 frames $/ \mathrm{s}$.

\section{Registration of the discharge glow with nanosecond time resolution}

The recording of the discharge glow in nanosecond time range was carried out with the aid of an electron-optical camera BIFO Ko11. Each frame exposure was 100 ns, the time interval between frames - from 100 ns. One of the obtained frame sequences is shown in fig. 6 The first three frames of the given sequence correspond to glow when the discharge electric current flows. On the subsequent images, an afterglow of a relaxing gas-discharge plasma is observed. This process may last for more than $2 \mu \mathrm{s}$. The source images are monochrome. For clarity, the intensity has been transformed into a color palette. According to the received frame series, the velocity of the left boundary of the discharge glow region was measured. The $\mathrm{x}$-t diagram of its movement was plotted and compared with the $\mathrm{x}$-t diagram of the movement of discontinuities obtained with the aid of high-speed shadow imaging under the same conditions. Comparison of more experimental data in the nano- and microsecond time ranges shows that the left boundary of the glow region of the gas-discharge plasma corresponds to the contact discontinuity $\mathrm{C}$. The analysis of the glow images shows that near the contact discontinuity $\mathrm{C}$ there exists a thin gas region of up to $1.5 \mathrm{~mm}$ in size. Its glow intensity is $1.5-2.5$ times higher than the glow intensity of the discharge plasma to the right of it. The geometry of the glow region was determined by the average distribution of the glow intensity along a straight line drawn horizontally through the center of the image. To explain the increase in the intensity of the glow in this area, we performed one-dimensional numerical simulation of the flow. 


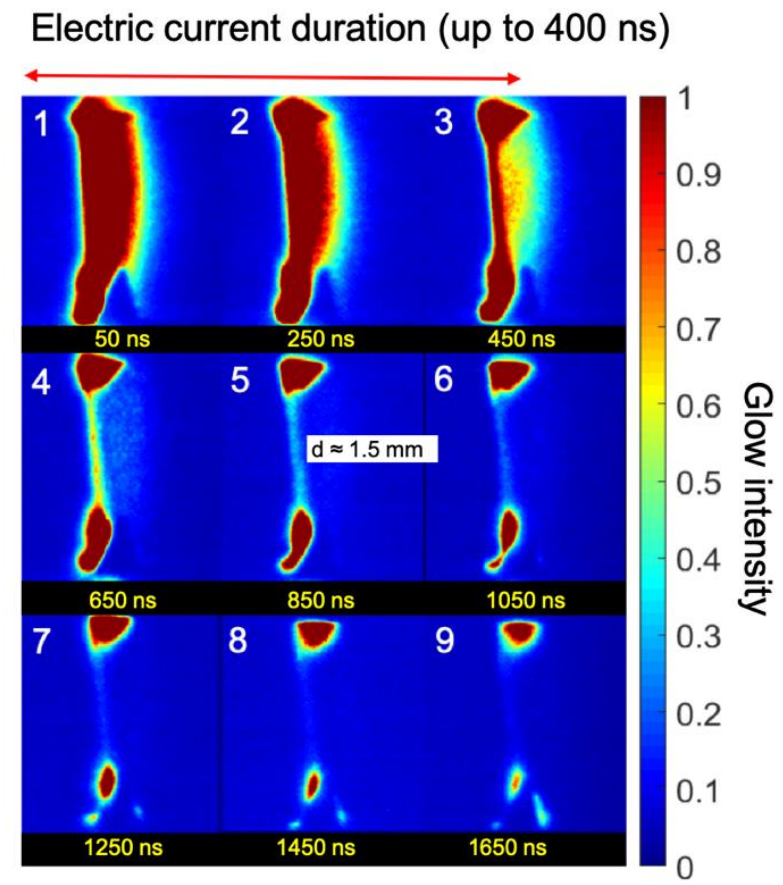

Fig. 6. Nine-frame images of the evolution of the discharge glow in front of the shock wave with Mach 4.7 at an initial pressure of 2 Torr. The distance from the shock wave front to the end of the discharge gap at the moment of the discharge is $1.3 \mathrm{~cm}$. Exposure / pause is $100 / 100 \mathrm{~ns}$. The triangle in the foreground is a reference point for distance measurements.

\section{Numerical simulation of the flow after the interaction of the discharge with the shock wave front}

The analysis of the images of the flow obtained by the two described methods showed that the flow in the center of the channel - far from the plasma sheets - in the first 5-7 microseconds after the discharge is close to one-dimensional. In order to analyze the evolution of gas-dynamic parameters in the flow in the central region of the channel with energy input, one-dimensional numerical simulation of the flow was carried out using the second-order Godunov scheme. The method applied to the problem under consideration is described in [13]. Fig. 7 shows the gas density distribution along the horizontal axis at the initial time moment and $1.5 \mu$ s after the discharge. On the graphs obtained, 4 significant regions can be distinguished: 1 - the jump region of gas-dynamic parameters behind the shock-wave front $\mathrm{S}_{\mathrm{o}}, 2$ - the region of the energy input (heated gas in the region of the discharge localization), 3 - the region between the shock wave $S_{2}$ and the contact surface $C, 4-$ region between the contact discontinuity $\mathrm{C}$ and shock wave $\mathrm{S}_{1}$. Regions 1 and 2 are set at the initial moment, 3 and 4 are formed after the discontinuity breakdown at the front of the initial shock wave So. It is important to note that on the calculated profiles, the discontinuity breakdown is observed both on the left and on the right boundary of the energy deposition region. In fact, it happens only on the left boundary (at the shock wave front $S_{o}$ ), the gas discharge on the right side does not have a sharp boundary and the conditions necessary for the Riemann problem are not realized. 

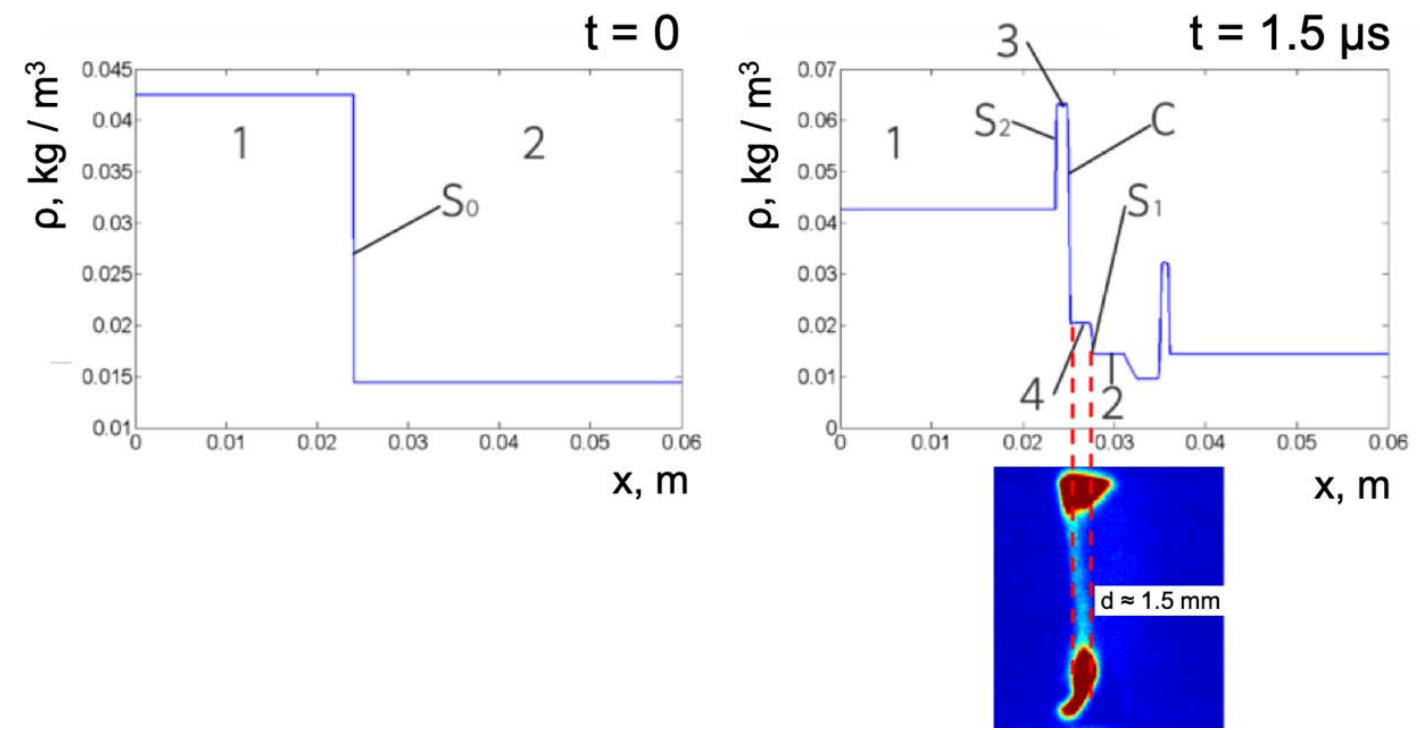

Fig. 7. Calculated density profiles at $t=0$ (left), $t=1.5 \mu$ s (right). The Mach number of the shock wave $S_{o}$ at the initial moment is $M=4 \cdot 3$.

The presence of the intense glow region near the contact discontinuity can be explained by an additional jump in the gas density between the shock wave $S_{1}$ and the contact surface $\mathrm{C}$ as a result of the shock-wave compression of gas in this region by the shock wave $\mathrm{S}_{1}$. An increase in density leads to an increase in the concentration and frequency of collisions of nitrogen molecules in metastable excited states. In this case, the rate of population of the radiating states and, accordingly, the intensity of the radiation, change.

\section{Conclusion}

The process of interaction of a discontinuity (shock wave) with a region of nanosecond ionization caused by the pulsed volume discharge with preionization from plasma sheets (sliding surface discharges) was visualized. The discharge was localized in front of the moving discontinuity. Panoramic methods were used: high-speed shadow imaging in a microsecond time scale (recording speed from 100 ooo to 525000 frames / s), high-speed recording of the discharge glow in a nanosecond time scale (time interval between frames / exposure - 100/100 ns). Mach numbers of visualized discontinuities reached 4.8. The obtained digital sequential frames were processed, the dynamics of discontinuities were compared with the results of a one-dimensional numerical simulation of the flow. Comparison of the calculation and experimental images made it possible to explain the distribution of the discharge glow intensity in the nanosecond time scale based on the dynamics of the discontinuities formed.

The work was conducted under the support of RSF Grant № 18-19-00672.

\section{References}

1. Kuo S.P. Shock Wave Mitigation by Air Plasma Deflector// Advances in Aerospace Science and Technology. Vol. 3. 2018. pp.71-88.

2. Lapushkina T.A., Erofeev A.V. Osobennosti vozdejstviya slabotochnogo gazovogo razryada na sil'nuyu udarnuyu volnu //Pis'ma v ZHTF. T. 43. № 5. 2017.pp. 17-23. [In Russian]

3. Matsuda A., Kondo Y., Aoyama N. Shock wave modulation due to discharged plasma using a shock tube //Mechanical Engineering Journal. Vol. 3.№ 6. 2016. pp. 1-12.

4. Annenkov V.A., Levin V.A., Trifonov E.V. Razrushenie udarnyh voln pri ih vzaimodejstvii s lokal'nym istochnikom energovydeleniya // Prikladnaya mekhanika i teoreticheskaya fizika. v. 47. № 2. 2006. [In Russian]

5. Settles G.S., Hargather M.J. A review of recent developments in schlieren and shadowgraph techniques //Measurement Science and Technology. Vol. 28, №4, 2017. 
6. Krehl P., Engemann S. August Toepler-the first who visualized shock waves //Shock Waves. Vol. 5, № 1-2. 1995. pp. 1-18.

7. Gerasimov S.I., Zubankov A.V., Kikeev V.A., Smirnov I.YU., Trepalov N.A., Gerasimova R.V. Issledovanie haraktera otrazheniya $\mathrm{v}$ model'nyh opytah pryamotenevym metodom vizualizacii // Nauchnaya vizualizaciya. T. 10. № 5. 2018. pp. 160-171. [In Russian]

8. Versluis M. High-speed imaging in fluids //Experiments in fluids.Vol. 54. No. 1458. 2013. pp. 1-35.

9. Kuznecov A.YU., Mursenkova I.V. Osobennosti izlucheniya ob"emnogo nanosekundnogo razryada v vozduhe pri vzaimodejstvii s ploskoj udarnoj volnoj // Prikladnaya fizika. № 5 . 2016, pp. 16-21. [In Russian]

10. Alferov V.P., Dmitriev L.M. Elektricheskij razryad v potoke gaza pri nalichii gradientov plotnosti//Teplofizika vysokih temperatur. v. 23. № 4.1985. [In Russian]

11. Rosini M.D. The Riemann Problem. In: Macroscopic Models for Vehicular Flows and Crowd Dynamics: Theory and Applications. UnderstandingComplexSystems.Springer, Heidelberg.2013. pp. 43-50.

12. Znamenskaya I. A., Koroteev D. A., Lutsky A. E. Discontinuity breakdown on shock wave interaction with nanosecond discharge // Physics of Fluids. Vol. 20. 2008.

13. Doroshchenko I., Znamenskaya I., Koroteev D., Kuli-zade T. When shock is shocked: Riemann problem dynamics at pulse ionization of a shock wave // Physics of Fluids. Vol. 24. № 10.2017.

14. I. Znamenskaya, A. Luckij, YA. Hanhasaeva, C. Czin'. Vzaimodejstvie chislennoj i eksperimental'noj vizualizacii pri issledovanii svojstv razryadov metodom analiza udarno-volnovyh konfiguracij // Nauchnaya vizualizaciya. T. 5, № 3. 2013. pp. 40-51. [In Russian]

15. Landau L.D., Lifshic E.M. Gidrodinamika. - Izdanie 4-e, stereotipnoe. // M.: Nauka. 1988. 736 p. [In Russian] 